\title{
Cultural aspects of Latino early childhood obesity
}

Lauren Clark

Susan L. Johnson

Mary E. O'Connor

Jane H. Lassetter

Brigham Young University - Provo, jane_lassetter@byu.edu

Follow this and additional works at: https://scholarsarchive.byu.edu/facpub

Part of the Other Nursing Commons, and the Pediatric Nursing Commons

\section{Original Publication Citation}

Clark, L., Johnson, S., O’Connor, M., \& Lassetter, J. L. (2013). Chapter 8: Cultural aspects of Latino early childhood obesity. In C. Beck (Ed.) Routledge International Handbook of Qualitative Nursing Research. London, England: Routledge Taylor \& Francis Group.

\section{BYU ScholarsArchive Citation}

Clark, Lauren; Johnson, Susan L.; O'Connor, Mary E.; and Lassetter, Jane H., "Cultural aspects of Latino early childhood obesity" (2013). Faculty Publications. 5174.

https://scholarsarchive.byu.edu/facpub/5174

This Book Chapter is brought to you for free and open access by BYU ScholarsArchive. It has been accepted for inclusion in Faculty Publications by an authorized administrator of BYU ScholarsArchive. For more information, please contact ellen_amatangelo@byu.edu. 


\title{
Cultural aspects of Latino early childhood obesity
}

\author{
Lauren Clark, Susan L. Johnson, \\ Mary E. O'Connor, and Jane Lassetter
}

\section{Introduction}

The problem of Latino childhood obesity ${ }^{1}$ is well known, and experts agree that the sooner it is addressed in a child's life, the better. Strong evidence from nationwide studies suggests that obesity begins in infancy for Mexican Americans. National data demonstrate the dramatic increase in weight-for-recumbent length above the 95th percentile (using the NCHS growth chart) among Mexican American children between National Health and Nutrition Examination Survey (NHANES) and the Third National Health and Nutrition Examination Survey (NHANES III) (Ogden et al., 2006). High rates of childhood obesity affect the long-term health potential of children, since childhood obesity tracks into adulthood - the older the obese child, the greater the chance he or she will become an obese adult (Guo, Roche, Chumlea, Gardner, \& Siervogel, 1994; Whitaker, 1997). Despite the well-documented problem of Latino early childhood obesity (Ogden, Flegal, Carroll, \& Johnson, 2002), less is known about Latino family and community cultural understandings of early childhood obesity and preferred approaches to support healthy early childhood feeding, nutrition, and weight status.

For clinicians, the challenge of caring for overweight children begins at diagnosis. Standards for body mass index (BMI) to classify overweight and obesity are clear (Ogden, Carroll, Kit, \& Flegal, 2012). Once diagnosed, clinicians can access a variety of evidence-based resources to guide their treatment plans and enlist the cooperation of families (e.g., Annesi, Pierce, Bonaparte, \& Smith, 2009; Foster et al., 2008; Holt, Wooldridge, Story, \& Sofka, 2011; National Association of Pediatric Nurse Practitioners, 2006). Although diagnosis and treatment initiation are challenging and complex processes for clinicians, prevention of childhood obesity is arguably more difficult. Helping families to understand the changes in lifestyles that would prevent obesity and incorporating such a discussion during a short office visit remain a challenge for pediatric clinicians. Effective childhood obesity prevention will depend on qualitative research to fill gaps of understanding about Latino families' cultural values and patterns of infant feeding that produce obese children. Qualitative knowledge about how Latino families rear children who are of normal weight would be more useful, as the strengths identified in those families and their social networks could be a basis for helping other at-risk families.

The purpose of our research was to explore the criteria used by Latino mothers, fathers, and grandparents to identify children from birth to 18 months of age who are normal weight, 
overweight, or obese; their descriptions of those children; and their preferred approaches for reinforcing childcare and feeding to achieve an "ideal" or healthy infant body shape. Specifically, we framed our research questions to address the kinds of behaviors, foods, and feeding patterns identified by parents and grandparents as contributing to early childhood obesity in their communities. We also investigated what Latino parents and grandparents consider to be appropriate interventions for infants or children who would be considered "obese" or "overweight" in their community. To accomplish this, we developed a methodology to help parents describe their children's weight and their attributions of parenting skills in caring for overweight, normal and underweight infants.

\section{Background}

We use the term "Latino" to refer to Mexican American and Mexican immigrant families who participated in our research. We identified a community, which we call Los Alamos Verdes, known to have a mixture of Mexican immigrants and older, established Mexican American families. One of our key informants referred to the area by its local name of "Little Mexico." The typical pattern of settlement in the area is characterized by single young adults and young families immigrating from Mexico to live with extended lateral kin. Families and friends from the same town in Mexico tend to reside together, especially during the early months after their arrival. Few of these young families have access to local grandparents, although they telephone Mexico occasionally and send remittances regularly. A major Catholic church is headquartered in Los Alamos Verdes, and offers a familiar focal point for new immigrants. Community life is characterized by busy schedules of lower-income young families settling into a routine of work and family life. New residents find work nearby, have children, and use the community health center for low-cost primary care. Eventually young families mature and some move to more established communities nearby.

Of the patients using the low-income urban community health center clinic where we recruited many study participants, more than $90 \%$ of immigrant families were Mexican (Young \& O'Connor, 2005). Even so, the clinical population demonstrated intracultural variation related to an urban or rural upbringing in Mexico, the length of residence in the US, processes of acculturation experienced in the US, and the specific kinds of syncretism they create as they merge and adapt their cultural lifeways over time. This kind of intracultural variation does not overshadow core cultural values about parenting and generations of cultural knowledge about feeding infants. Each family had a somewhat unique approach to child feeding, but an identifiable set of common cultural beliefs and values about child growth and infant feeding is also identifiable. Our clinical experience and a history of ethnographies on Latino child and family health suggest that Mexican Americans share historically rooted expectations for health care and early childhood growth and feeding (Alexander, Sherman, \& Clark, 1991; Clark, 2002; Clark \& Redman, 2007; Kay, 1977).

Los Alamos Verdes has experienced patterns of health disparity common in Latino communities such as higher rates of obesity, diabetes, and complications from diabetes in comparison to the national average (Vega, Rodriguez, \& Gruskin, 2009). Type II diabetes among adults, which is associated with obesity, affects nearly every family. Complications of diabetes (such as amputations and kidney failure) were common, according to our informants who readily linked obesity to these outcomes. Even with high levels of need, there are few community-level, culturally competent interventions available. Clinical care of individuals already affected with diabetic complications is most common, rather than community-wide prevention efforts geared toward those who are at risk but not yet overweight, obese, or diabetic. Our overall goal was to 
provide a background of ethnographic data that could inform the development of new clinical and community practices specific to the cultural needs of the local Latino population.

\section{Methodology}

As a team of clinician-researchers, we were familiar with a community we will call "Los Alamos Verdes," a geographically identifiable area in the Denver, Colorado, metropolitan area. We had worked with families in the area for about two decades each as a nurse-anthropologist (LC), pediatric nutritionist (SJ), and pediatrician (MO). Another team member joined us near the end of our work (JL), extending some of our methods in her research. Our ethnographic work reported here spanned several studies and took place over 15 years. For many nurseanthropologists, funded research is a slice in a long trajectory of ethnographic fieldwork conducted over time and across several initiatives. All of our research was conducted with the approval of the appropriate human subjects review boards.

\section{Design}

The purpose of our focused ethnography was to describe the cultural constructions of intergenerational Latino parents and grandparents in Los Alamos Verdes about food, feeding, child growth, and childrearing, and how they acted on those understandings.

Our focused ethnography incorporated a combination of participant observation in the community, focus groups, and semi-structured individual interviews with mothers, fathers, grandmothers, and grandfathers. Another aspect of the ethnography described elsewhere included interviews with biomedical pediatric health care providers about their views of the cultural aspects of Latino child health and obesity prevention in Los Alamos Verdes (Johnson, Clark, Goree, O'Connor, \& Zimmer, 2008). We also conducted a related study with curanderos who were knowledgeable about Latino family health and nutrition (Clark, Bunik, \& Johnson, 2010).

\section{Sampling}

To understand Los Alamos Verdes, we sampled social situations and clinical care settings over time. For the focused ethnography with parents and grandparents, we set our inclusion criteria such that parent/grandparent participants all had a child/grandchild 18 months of age or younger. They all lived in or near Los Alamos Verdes. Acculturation of participants was measured on the five-point Short Acculturation Scale for Hispanics (SASH) (Marín, Sabogal, Marín, OteroSabogal, \& Perez-Stable, 1987). By definition, cultural knowledge is widely shared among parents and grandparents, regardless of parents' own or their children's weight status, so inclusion criteria did not select for an overweight sample. To recruit parents and grandparents, we worked with health care providers at two clinics and two affiliated Women, Infants, and Children Supplemental Nutrition Program (WIC) programs. Providers briefly explained the study purpose and encouraged prospective participants to meet us in the waiting room for more information. We also attended weekly public health immunization clinics where we described our study in English and Spanish to waiting parents and encouraged waiting parents/grandparents to approach us if they were interested in learning more about the study. 


\section{Methods}

A cornerstone of ethnography is fieldwork, characterized by participant observation and formal and informal interviews recorded in fieldnotes and transcripts (Spradley, 1980; Angrosino, 2007). Informal conversations were easily guided toward our topic of interest, and these interviews included conversations with the nuns at the Catholic church, visits with neighborhood women in their homes, and discussions with curanderos about their views of local health concerns. Formal interviews followed an interview guide designed for a focus group or individual interview.

Participant observation led us to attend mass, baptisms, and community fiestas at the local Catholic church. We subscribed to the local Spanish-language newspaper, listened to Spanish radio stations, and periodically visited botanicas and tiendas (local herb shops and stores) to identify key informants in the community (such as the curanderos) and to observe the range of child health products and parents' shopping behaviors. We attended neighborhood meetings to observe how people collectively identified and addressed neighborhood concerns. Fieldnotes about our experiences recorded how people in Los Alamos Verdes talked about childhood obesity, in particular, and other health issues. Our fieldnotes also contained reflections about how behaviors we observed differed from or expanded on what participants said were their usual behaviors. Our fieldwork and participant observation provided complementary background data, offered a wider context to frame our results, and provided a means of informal member-checking findings from focus groups and interviews in successive conversations.

Focus groups were constituted to explore specific questions about shared cultural knowledge informing early childhood feeding practices and child body shape and size preferences. Focus groups are well suited for investigating complex behaviors and motivations when variation among group members is likely high (Morgan \& Krueger, 1993). Participant observation and clinical experience primed us to develop questions to explore specific cultural aspects of childhood obesity (see Table 8.1).

Participants included 60 parents and grandparents and 38 health care providers across 14 focus groups. We gave each parent a $\$ 25$ gift certificate to a local grocery store chain. Providers were offered lunch before the focus groups. Gender-specific focus groups were arranged for parents and grandparents. These consisted of mothers/grandmothers and fathers/grandfathers. These groups explored gendered knowledge in households and avoided the gender-based dominance possible in mixed-gender focus groups. Generation-specific groups were hosted with mothers only to explore tensions between genders and generations. Focus groups were hosted at libraries and clinics located on bus routes, and participants were invited to join either English or Spanish groups.

A series of six silhouettes of a Latino child approximately 9 months of age and of increasing adiposity were commissioned (Figure 8.1). In the silhouettes, the first child depicted appears considerably underweight and the sixth child depicted appears very overweight. We used the silhouettes in focus groups to open discussion about the topic of linguistic indicators of childhood health and the social value of different body sizes and levels of adiposity. We also asked projective questions about the kind of family the infant of each body size might have, and how the lightest and heaviest infants were cared for in their families. Fetterman (1989) refers to visual images as "can openers" that increase familiarity among focus group members and elicit projective responses from them.

Our silhouettes maintained key features of earlier silhouettes developed by Kramer and colleagues (1983). All silhouettes used the same infant face, size, shape, and posture. The boys had a blue diaper, and the girls had a pink diaper and a pink hair bow. We modified the original string of silhouettes by providing colored shading to represent Mexican American infants' skin 
Table 8.1 Basic outline of focus group questions for parents/grandparents about childhood feeding and weight

Topic Specific questions and prompts

Introductions, consent process,

ground rules of focus group

What characteristics do parents and grandparents identify as indicators of obesity and overweight?

What kinds of behaviors, foods and feeding patterns or other environmental situations are identified by parents as contributing to early childhood obesity in the community?
Show the infant silhouettes

Start with the smallest baby

- What words would you apply to this baby? How would you describe this baby? (probe for both physical descriptors and for behavioral or personality descriptors)

- If this were your baby's body how would you describe your baby?

- How would your doctor or nurse talk about your baby?

- How would you prefer that they talk about your baby's weight status?

- What would you think of a mother who has a baby that looks like this?

Repeat the questions with the largest baby

Looking at all the baby drawings, at what point is a baby too

big to be healthy? Which picture would represent that?

Show the growth chart.

Have you seen this kind of a chart before? Explain what it tracks with basic information.

Show the obese child growth chart. Explain that it shows the child gaining weight at a rate faster than the child's growth in height

- If a doctor or nurse showed you this growth chart, what would you think?

Why do you think some children are overweight and others are not?

How has your world changed since you were a child (in terms of food and activity?) How do you think this affects children? Do you think your child might become overweight one day? Is there anything you can do to keep your child from becoming overweight?

How do you know when babies are hungry? How do you know when babies are full?

Scenario: Let me tell you at story about a very nice family. There was a mother, Maria, a father, Jose, and three little girls. They lived with Maria's mother. The grandmother watched the girls during the day while Maria worked cleaning houses. The father played with the little girls every night after work, and took them outside on their tricycles. They got together on the weekends with their family for barbecues and birthday parties, but during the week the family ate together in the morning and the evening. The youngest girl, Claudia, turned 1 year old and weighed 32 pounds. The doctor was very concerned, and asked the mother what was causing this incredible weight gain for the baby. 


Topic Specific questions and prompts

Was the doctor right to be worried about Claudia's weight?

What do you think was going on with the family that Claudia was gaining so much weight?

How did the grandmother and the dad fit in? In what ways were they involved in managing children's feeding and weight?

What advice would you give to Maria about the baby?
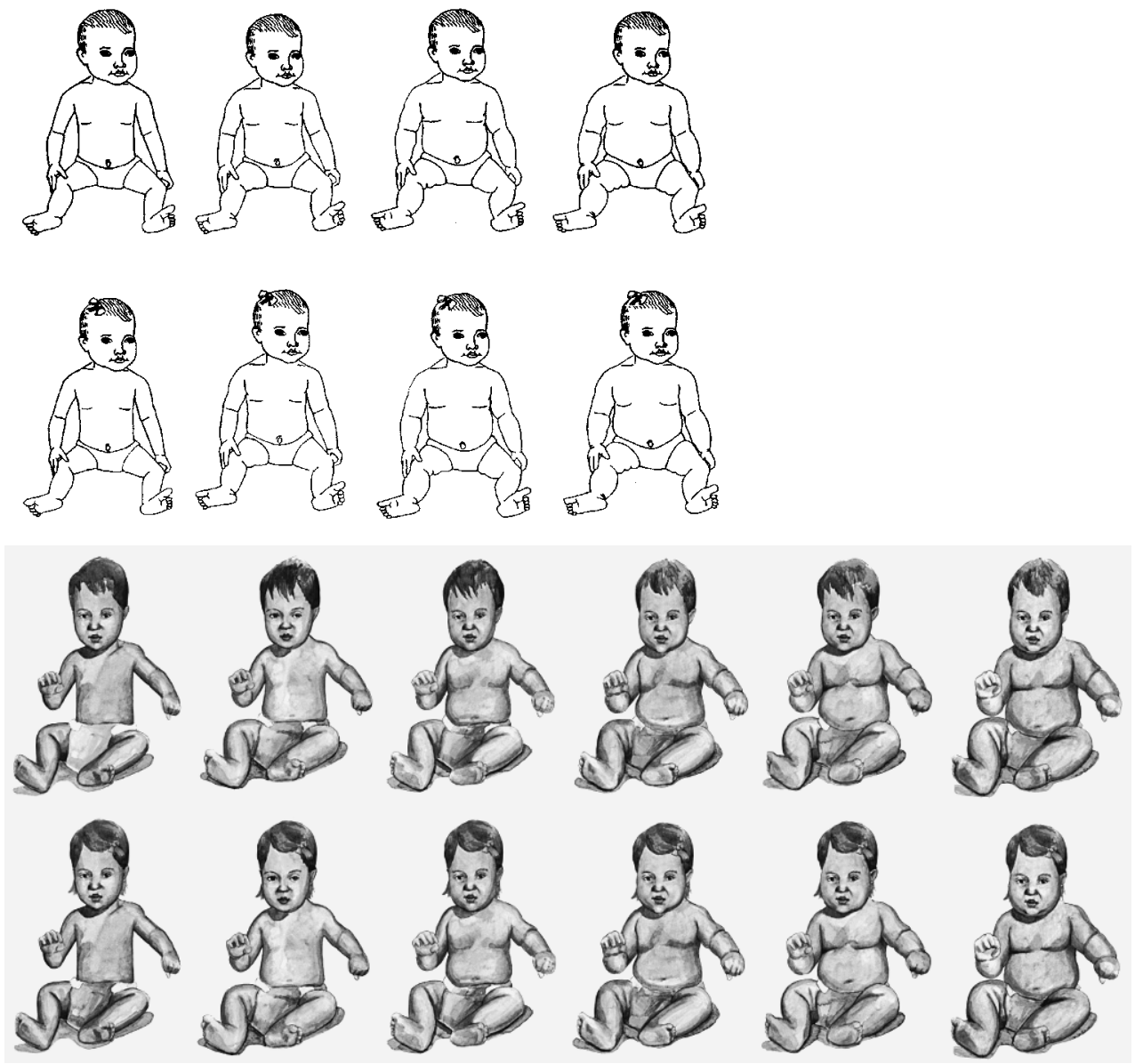

Figure 8.1 Infant silhouettes developed by Kramer, Barr, Leduc Boisjoly, and Pless (1983, p. 331) (above) and those commissioned for this research study

Source: Reprinted with permission from Elsevier Limited. 
pigment and suggest curvature and form. After the first focus group we learned that the heaviest infant depicted was not viewed as very large at all. As a result, we added two new drawings at the heavier end of the weight continuum. These heaviest infants facilitated discussions about the value and meaning of very large infant bodies, eliciting parents' and grandparents' linguistic indicators and attributions about infants and caregiving relationships. The silhouettes sparked participants to share stories of the kinds of families, particularly the kinds of mothers, who reared children at the weight extremes.

Semi-structured interviews included the technique of freelisting (Weller \& Romney, 1988). The rationale underlying freelisting is that cultural knowledge is, by definition, shared. Another assumption is that cultural knowledge is not equivalent to scientific knowledge, and parents and professionals can have different (but not "wrong") knowledge structures. Freelisting suited our research purpose by systematically eliciting emic knowledge of Latino early childhood obesity risk factors and protective factors. Freelisting matched the needs of a clinic-based interview setting. Lengthy, private individual interviews were impractical given parents'/grandparents' time constraints and the clinics' space constraints. Freelisting can be done in a short period of time and without a tape recorder. We conducted the interviews ourselves, and also hired trained, bilingual, bicultural women of childbearing or middle age who were familiar with Los Alamos Verdes to collect freelists.

The freelisting interview began by asking the parent or grandparent their thoughts about why Mexican or Mexican American children are overweight. This could be a confrontational question. To diffuse any reference to their own children, we framed the question as a general one, and asked for their expert opinion about Mexican children in their acquaintance generally. The participant would consider this question then begin talking about the contributors to overweight among local children. The researcher would transcribe each answer verbatim (in either or both English and Spanish), paying careful attention to the exact words and the order of the reasons listed. After the participant stopped listing answers, the researcher would provide a prompt, such as "Can you think of any more reasons?" Other elicitation techniques included nonspecific prompting, reading back the list of items and asking if there are more, and using listed items as semantic cues for other, similar items (Brewer, 2002). If the participant continued freelisting, the researcher would continue to transcribe the answers as before. The probes for more responses would continue until the participant said that his/her list was complete and he/she had nothing more to add.

The second freelisting interview question was "What are some behaviors that protect Mexican and Mexican American children from becoming overweight?" Again, the researcher would listen, transcribe verbatim, and probe until the participant said the list was complete. Then the participant would add stories or information she or he considered pertinent. This part of the conversation was tape-recorded. After the interviews, participants were given a small gift (\$10 long-distance telephone card or grocery store gift card) and thanked for their time.

\section{Data analysis}

Interviews and focus groups were transcribed. Fieldnotes were also entered into the dataset, either appended to the transcripts or as separate documents. The silhouettes were used in focus groups to elicit discussion, and those data were also part of the focus group transcript submitted for analysis. Analysis of discourse and narrative was managed with a qualitative data management program, AtlasTi (Scientific Software 6.2, 2010) in the original language (English or Spanish) of the interview. A different software program, Anthropac (Analytic Technologies, 1996), was used to analyze freelisting. One of us (LC) inductively developed a coding dictionary to index segments 
of text that referred directly or more obliquely to our interest in the cultural and family context of childhood feeding, growth, and the development of overweight. By indexing each segment of data on the same topic with the same codeword in the AtlasTi software, we identified hierarchies of meaning and categories of analysis. Focus group transcripts, interviews, and fieldnotes were analyzed for themes and patterns to build evidence across the different aspects of the study (Carey, 1994; Morse, 2001).

Analysis of freelists was handled in a separate analysis based on two ideas. First, "things most familiar or most important to people will be mentioned before things that are less familiar or less important." Also, "people who know a lot about a subject [in this case early childhood feeding and obesity] will have more to say (longer freelists) about it than people who know less" (Fleisher \& Harrington, 1998, p. 79). The first step in the analysis of freelists was to code the data. Often, lists will contain a phrase or sentence that can be reduced to a codeword encapsulating meaning. Other phrases on other participants' lists may share the same meaning, and would be assigned the same codeword, consistent with the coding process used in other kinds of qualitative research. Analysis of freelists results in frequency of mention of each idea or codeword (a percentage of respondents who listed that idea), an average rank of each codeword (meaning rank order among the codewords), and a salience score for the codewords. The salience score is based on two other scores: frequency and rank. As a result, salience is a measure of how much knowledge informants share and how important that knowledge is in the cultural domain. To generate these various frequencies, rankings, and scores, Anthropac software was used. Even without the software, salience is easy to calculate. It involves dividing the rank order of a codeword by the number of items in an individual's freelist. After that, the researcher sums the salience scores for each item across respondents and divides by the number of respondents to arrive at a composite salience value. Codewords that were most salient in the composite analysis were viewed as culturally agreed-upon indicators of early childhood obesity risk, and those that were not salient were considered idiosyncratic beliefs.

\section{Results}

A total of 160 parents and grandparents participated in the interviews (83 mothers, 48 fathers, 21 grandmothers, and 8 grandfathers). Participants in the interviews were not invited to participate in focus groups. In general, participants in the focused ethnography were Spanish speakers oriented toward traditional values and behaviors. The language of the interviews was predominantly Spanish (75\% of the interviews). Acculturation was measured on the five-point Short Acculturation Scale for Hispanics, with a lower score indicating lower acculturation (SASH mean $=1.9$, range 1.2-4.8). Parents and grandparents had a mean body mass index (BMI) of 28 (range: 19-38), indicating they were in the overweight category (a BMI of 25-30 is indicative of overweight). Cultural themes, freelists of obesity-producing and obesity-preventive behaviors for young children, and data from silhouettes about the language of childhood obesity comprise the ethnographic results.

\section{Themes}

Themes describe the cultural knowledge of Latino parents and grandparents in Los Alamos Verdes about food, feeding, child growth, and childrearing, and how this knowledge informs their behaviors. Each theme was identified across data sources and expresses central cultural beliefs (DeSantis \& Ugarriza, 2000). 


\section{A Mexican way of feeding babies}

Child feeding displayed and embodied ethnic identity. Literally, feeding is an act of embodiment of food given to sustain a child's body and shape it to fit cultural values about infant body type. The Mexican way of feeding babies is how the community viewed their child feeding practices.

\section{Complementary feeding}

Weaning foods or first foods are known as complementary foods, specifically because they complement breast milk or infant formula. Adhering to a Mexican way of feeding babies is a dismissal of physician and nurse recommendations, specifically the recommendation for exclusive breastfeeding or infant formula until 6 months of age. "We go against what the doctors say," said one mother. "Like when her, the doctor, said don't feed her until she's 7 months. I started her at one month." Another mother said, "What we do that most Americans don't do, is feed them food right away." The evidence-based knowledge that guides health care recommendations about what and how soon to feed infants non-milk foods differs from the emic knowledge of how to feed a Mexican baby. Early infant feeding is part of the social value placed on mealtimes in Mexican families. "When you're sitting at the table, everyone should be eating." Because babies are curious and reach for food and utensils, some mothers identified this as readiness to join in eating regular food with the family.

Types of complementary foods varied, but were often introduced to infants in their first few months of life. "I mean, my son at 6 months was eating a tortilla with frijoles. Dip it, give it to him," said one mother. Traditional complementary foods included caldo (soup) or probaditas or "tastes" of beans, eggs, potato, or tortillas. Smoothies or liquados, candy, or "anything" were answers given as we probed about common complementary foods.

\section{Ubiquity of the bottle}

Bottle feeding is another aspect of the Mexican way of feeding babies. Our participant observation identified bottle feeding as beginning early, usually shortly after birth, and continuing until ages 2 or 3. Long-term bottle-feeding with high-calorie strawberry milk or chocolate milk was common. When asked why flavored milk instead of regular formula or low-fat cow's milk, parents said they doubted their children would "like" anything else. Guidelines from the medical community about milk-only fluids in the bottle and weaning from the bottle shortly after the first birthday may have been offered, but local practice deviates from those recommendations. Our photographic research emphasized the ubiquity of the bottle in daily life of children 12-18 months of age, and the early pairing of child feeding with television viewing (Clark \& Zimmer, 2001).

\section{Indulging the baby}

Giving babies flavored milks with extra calories and no additional nutritional value is one way of indulging babies, giving them what they want, and demonstrating the parenting value of attentiveness to a baby's desires. Participants believed a baby should not be restricted, but shown love by a responsive parent. A mother of an overweight 1-year-old son was encouraged by the child's health care provider to monitor and restrict unnecessary caloric intake. She responded, "At a year, I wouldn't get my son into a diet. I would just rather let him stick to being fat for a little while." Being fat was presumably the baby's chosen and preferred way of being, or at a minimum, the way that babies "should be." Another mother, when speaking of a sweet treat offered to her overweight nephew, said, "His parents knew the baby would like it, so they gave it to him. Of course, any kid would like it." The focus group developed this theme further, with an exchange between mothers: 
Mother 1: I want to give the baby what he wants.

Mother 2: They want anything that's sweet.

Mother 3: My kid loves chocolate.

Mother 1: Sometimes I let 'em taste suckers, so I know he's gonna like it, so I give him a little bit, a taste of it. His daddy gets mad at me though. "Quit giving him that, you'll give him a stomach ache."

These are examples of how childrearing beliefs translate into child feeding behaviors and aligned with Mexican self-identity. The same nurturing environment and parenting behaviors that are associated with sensitivity to children's needs and their self-directed development are also linked to parental indulgence in child-directed feeding behaviors driven by flavor and sweetness that contribute to over-feeding and under-nutrition.

\section{When weight is a problem}

According to parents and grandparents, children being overweight is not always a problem, even when a child's weight-for-length meets clinical definitions of obesity. In Los Alamos Verdes, weight is a problem when it is a social liability, a functional or developmental hindrance, or a gendered issue. It is through these social and cultural evaluations, rather than by knowing weight on a scale, that parents and grandparents come to know that a child's weight is a problem.

\section{Social age-related problems}

The negative social consequences of children's obesity are clear to parents, who say "When they go to preschool, or when they're about three years old, then they start to be teased by their friends. Then they won't invite them to play because they're fat." Other parents say the social consequences arrive most profoundly at a later stage. "Don't worry until kindergarten. Let them be as fat as they want until kindergarten. Kindergarten is a problem, they might get teased." Others saw the problem occurring even later for boys: "It's a problem when boys are adolescents. Because then they're interested in girls."

\section{Functional health and development problems}

Not only is excess body weight a social problem, but a functional and developmental problem as well. Parents and grandparents noted that some babies were too big for their car seat, too big for diapers, and so fat they were "having problems with walking" or moving ("tienen problemas para caminar" or "para movimientos"). Overweight babies "can't breathe" and develop both health and developmental problems. An overweight child is not a problem until weight becomes a functional issue for the parent or child.

\section{Gendered aspects of obesity}

The gendered nature of body weight, particularly at adolescence, identifies young men as more "like their Dads" and manly if they are large, and young women less attractive and less desirable if they are overweight. "Girls should be nice and pretty, skinnier" than boys as they get older. "The girl can be fat until the quinceañera," or 15th-year coming-out celebration. Then they should be "nice and pretty, skinnier." For these individuals there was little realization that being overweight early in childhood could make it more difficult to be "skinnier" as adolescents.

To illustrate the family pressures to socialize boys into men through food, a woman told of her brother-in-law, who was overweight and had an overweight son. The story illustrates how the child was taught to eat like a man, a Mexican man, and became overweight like his father. 
I asked him, "Why are you feeding your son so much? Especially if you are having a hard time losing the weight?" I'm not too sure they are really thinking about the whole outcome later on. Hispanic people eat a lot of fattening things, pork, and he doesn't have a problem sitting down with a big ol' thing of grease, chicharrones (fried pork skins), and it's like "Here, son." So it's hard for my nephew to lose weight with his Dad doing that. It's mostly the boys that have the problems, so whatever the Dad eats, the boy has to eat.

Mexican foods and celebrations inscribe ethnic and gender identities. Eating particular foods and food quantities forges community bonds. Baptisms, birthdays, and communions were formal occasions to prepare food and spend the day eating, as were weekend barbecues where children learned how to eat and enjoy ethnic foods.

\section{Freelists}

Parents and grandparents freelisted practices they believed to be responsible for the development of childhood overweight (Table 8.2). All of the most salient responses were food-related rather than activity-related. None addressed the feeding interaction between parents and children (such as authoritarian feeding styles) or feeding practices (like "topping off" each feeding by encouraging intake beyond satiety cues). Most common in the freelists were food items such as sweets, junk food, greasy food, or breads/flours/tortillas. Few participants noted that bottle feeding or too many bottles could contribute to children's obesity $(n=2)$, or that flavored milks $(n=1)$ might be adding too many calories to the diet. Two parents thought that breastfeeding may contribute to children becoming overweight.

Parents and grandparents also free-listed practices that protected against overweight: Eating vegetables and fruits, and (to a lesser degree) engaging in physical activity formed a discernible core of belief. The remainder of the protective factors were a combination of food prohibitions mirroring the risk factors (greasy foods, sweets, junk foods) and popular-culture ideas about water, white meats, and juice. For infants, juice is not considered a protective factor among health care providers, but rather a risk factor for unnecessary calories, especially when added to the calories obtained from formula or milk. The perception that juice is healthy and promotes a healthy weight could be registering the influence of WIC-provided food coupons for juice given to

Table 8.2 Parents' and grandparents' freelisted responses to the question, "Why are Mexican or Mexican-American children overweight?"

\begin{tabular}{lll}
\hline Item & Frequency & Smith's S (Salience Score) \\
\hline Tortillas & 29 & 0.310 \\
Fast food & 33 & 0.268 \\
Eating too much & 27 & 0.264 \\
Sweets & 33 & 0.213 \\
Soda & 28 & 0.208 \\
Junk food & 26 & 0.188 \\
No activity & 23 & 0.111 \\
Grease & 21 & 0.211 \\
Bread & 19 & 0.180 \\
Red meat & 16 & 0.131 \\
Flour & 14 & 0.154 \\
No los cuida (not taking care of them) & 13 & 0.096 \\
\hline
\end{tabular}


Table 8.3 Parents' and grandparents' freelisted responses to the question, "What are some behaviors that protect Mexican and Mexican-American children from becoming overweight?"

\begin{tabular}{lll}
\hline Item & Frequency & Smith's S (Salience Score) \\
\hline Eat vegetables & 39 & 0.373 \\
Engage in physical activity & 44 & 0.358 \\
Eat fruits & 33 & 0.304 \\
Don't allow grease & 24 & 0.214 \\
Eat healthier foods & 17 & 0.179 \\
Don't allow sweets & 19 & 0.157 \\
Don't eat too much & 14 & 0.145 \\
Have scheduled feedings & 13 & 0.133 \\
Drink water & 17 & 0.124 \\
Don't allow soda & 18 & 0.122 \\
Eat white meat & 14 & 0.107 \\
Eat soup or caldo & 11 & 0.101 \\
Drink juice & 13 & 0.098 \\
Don't allow junk food & 13 & 0.085 \\
\hline
\end{tabular}

breastfeeding women and infants. With a few exceptions, beliefs elicited by the freelisting procedure were congruent with evidence-based medicine (Table 8.3). It seems that lack of knowledge was not the underlying root cause of infant obesity in this group.

\section{Silhouettes and the language of childhood obesity}

On the continuum from very thin to very overweight infants, parents used anchor terms for the larger children such as gordo/a or gordito/a. The three largest infants were considered in the category of gordo. Gordo literally means "fat." Gordito is a euphemistic diminutive literally translated as "little fatty." Gordito may be considered flattering or even a term of endearment in a family, and does not convey a clear message from a health care provider to a parent about body weight when used in a clinical encounter. Bien gordo was the term used for the two drawings in the middle of the weight continuum, with the term referring to a well-formed, robust child who is appropriately proportioned. Sobre peso means "overweight," and is a clear way of discussing a child's overweight status without accidentally lapsing into gordito and confusing the message. El peso que debiera means a child who weighs what he should, even if that weight appears to a parent to be too thin or flaco.

Focus groups spent quite a bit of time discussing how children who were of the appropriate weight were sometimes viewed as too thin, often because overweight siblings and cousins were used as the reference group. El peso que debiera (the weight they should be) was suggested as a way of referring to appropriately sized infants to reassure parents that they are not too thin. Más Gordito is, literally, "more fat," as is pasadito de peso, and both are probably too colloquial to get a clear weight message across, although you will hear parents use these words. Parents and grandparents perceive the infants in the middle of the spectrum to be "normal" or "ideal." They also view the slightly slimmer infants as more likely to be breastfed, and the fattest infants more shockingly obese when they discuss the girl silhouettes than the boy silhouettes. When asked at what point an infant was "too fat" or "obese," parents indicated the heaviest two infants in the pictorial series, but also referred to the thematic elements describing when health is a problem. In those instances, the body weight was considered "obesity" if the child was a girl, was being teased, or was "too big to fit" into diapers or the car seat. 


\section{The context of healthcare in the urban immigrant community}

Cultural themes and freelists are contextualized by a political economy that embeds differential power in relationships between health care providers, health care agencies, immigrants, and other residents in Los Alamos Verdes. The community health center pediatric/teen clinic does serve as a medical home for children and teenagers in the community. It provides well-child care and care for chronic problems and acute illnesses and attempts to match families with a regular provider. It is also the site of a WIC clinic. However, many Latino families rely on a patchwork of health care services. They may seek immunizations from public health clinics, illness care from free clinics or emergency departments, and well-child care from a school-based health center, or they may forego child health services altogether until an emergency looms. Health care providers are uncertain how to broach a conversation about a child weight issue if they fear the family might sever their tenuous contact with the health care setting over a linguistic error or misunderstanding. Providers' challenges communicating in Spanish to parents with variable levels of health literacy require thoughtfulness and time that may be at odds with the busy pace of the community health center environment.

In the worst case, parents given hasty assessment results about child weight status could launch an over-zealous campaign to slim their child. Relying on cultural beliefs that tortillas or greasy food or red meat are responsible for overweight, they may decide to alter the infant's diet significantly. Without a thoughtful coordinated plan for weight monitoring and family-level behavioral feeding changes, providers are justifiably concerned that parents could launch an inadvisable child slimming effort that could threaten healthy growth and development. Without continuous follow-up or contact with the clinic, the results could be disastrous. As one public health nurse said, "I think we [at the immunization clinic] see that child on such a limited basis, I would be reluctant to encourage a parent to decrease the feedings of a baby less than twelve months, because I'm not going to have any follow-up with that child."

\section{Discussion}

Applying focused ethnographic results in community outpatient clinics can improve the health care experience for families and health outcomes for children. Because many parents ask how their baby is growing during well child checkups, health care providers can use cultural knowledge and community preferences about child body size to start a conversation. Health care providers identify the protective effects of breastfeeding and associate childhood obesity with prolonged bottle feeding, calorically dense flavored milks, over-feeding, and a host of other issues that map approximately, but not completely, on the cultural knowledge of parents and grandparents (Johnson et al., 2008).

Intergenerational disagreements about how to best feed a baby can be tense. Clinicians can prepare parents to introduce current biomedical recommendations at home with other family members. Such recommendations would value traditional feeding practices like breastfeeding and appropriately timed, high-fiber and low-fat complementary foods (like pinto beans and corn tortillas) typical of traditional Mexican cuisine. Reinforcing parents' cultural knowledge that fruits, vegetables, and physical activity prevent obesity is relatively easy for clinicians, since most families report that children like fruits and playing outside.

The cultural belief that a boy should be big like his father may partially explain the increased obesity rates in school-age Hispanic boys. The results from NHANES 2007-2008 show the highest rates of obesity for all race and ethnic groups to be among Mexican-American boys aged 2-19 years when compared to non-Hispanic white or black boys and Mexican-American girls. 
In infancy and toddler years, Mexican-American boys surpass Mexican-American girls as twice as likely to be overweight (weight/length $\geq 95 \%$ for children $<2$ years of age) (Ogden, Carroll, Curtin, Lamb, \& Flegal, 2010). Intergenerational involvement in feeding, the role of the grandparents and extended kin in multi-generational households, and cultural expectations for body size are topics worthy of additional research.

The cultural aspects of Latino childhood obesity are part of the broader topic of the social determinants of health. Latino families throughout the US encounter structural determinants of physical activity and healthy eating, from living quarters without backyards to lack of transportation during the daytime for women at home with children. Neighborhoods viewed as unsafe and lacking sidewalks and streetlights are a persistent reason for lack of outdoor playtime for children, and the relatively high cost of organized youth sports programs further discourages physical activity. Daily walks for mothers and their toddlers set a pattern of family physical activity. Walking groups for urban Latinas are a culturally congruent health promotion intervention with promise for further development (Clarke et al., 2007; Keller \& Cantue, 2008). Food deserts, or neighborhoods without access to affordable full-service grocery stores, could be addressed through public policy to benefit many urban communities.

\section{Conclusion}

Despite widespread media attention and scientific information about childhood obesity, health care providers encounter in practice a common refrain from parents of overweight children: "What do you mean, my child is overweight?" The mismatch between parents and health care providers in the cultural construction of childhood obesity is a classic example of how to apply a focused ethnography to improve cross-cultural clinical interactions. We know that how parents define childhood weight status in their own families and within their local socio-cultural environments is as culturally specific as providers' clinical definitions of childhood obesity. By asking, "What do you mean, my child is overweight?" the parent also presents a challenge to the provider to explain the scientific definitional characteristics of obesity in a sensitive, culturally competent manner and enlist parental involvement in establishing a "normal" weight for the child in biomedical as well as social and functional terms. Improving the health care of young children who are already overweight or at risk for overweight depends on structuring a dialogue with parents based on evidence about obesity prevention integrated with an understanding of cultural norms and feeding practices specific to the family.

\section{Note}

1 We use obesity in this article to identify the children who are overweight with a BMI $>85$ th percentile or above the 95th percentile and officially categorized as "obese" (Ogden, Carroll, Kit, \& Flegal, 2012).

\section{References}

Alexander, M. A., Sherman, J. B., \& Clark, L. (1991). Obesity in Mexican-American preschool children: A population group at risk. Public Health Nursing, 8, 53-58.

Angrosino, M.V. (2007). Naturalistic observation. Walnut Creek, CA: Left Coast Press.

Annesi, J. J., Pierce, L. L., Bonaparte, W. A., \& Smith, A. E. (2009). Preliminary effects of the Youth Fit for Life protocol on body mass index in Mexican American children in YMCA before- and after-school care programs. Hispanic Health Care International, 7(3), 123-129.

Brewer, D. D. (2002). Supplementary interviewing techniques to maximize output in free listing tasks. Field Methods, 14(1),108-118. 
Carey M.A (1994). The group effect in focus groups: Planning, implementing, and interpreting focus group research. In J. M. Morse (Ed.), Critical issues in qualitative research methods (pp. 225-241). Thousand Oaks, CA: Sage.

Clark, L. (2002). Mexican-origin mothers' experiences using children's health care services. Western Journal of Nursing Research, 24, 159-179.

Clark, L., Bunik, M., \& Johnson, S. L. (2010). Research opportunities with curanderos to address childhood overweight in Latino families. Qualitative Health Research, 20(1), 4-14.

Clark, L., \& Redman, R. W. (2007). Mexican immigrant mothers' expectations for children's health services. Western Journal of Nursing Research, 29, 670-690.

Clark, L., \& Zimmer, L. (2001). What more we learned about Mexican-origin children's health from a photographic research component. Field Methods, 13(4), 303-328.

Clarke, K. K., Freeland-Graves, J., Klohe-Lehman, D. M., Milani, T. J., Nuss, H. J., \& Laffrey, S. (2007). Promotion of physical activity in low-income mothers using pedometers. Journal of the American Dietetic Association, 107, 962-967.

DeSantis, L., \& Ugarriza, D. N. (2000). The concept of theme as used in qualitative nursing research. Western Journal of Nursing Research, 22(3), 351-372. doi: 10.1177/019394590002200308.

Fetterman, D. M. (1989). Ethnography step by step. Newbury Park, CA: Sage.

Fleisher, M. S., \& Harrington J. A. (1998). Freelisting: Management at a women's federal prison camp. In V. C. de Munck \& E. J. Sobo (Eds.), Using methods in the field: A practical introduction and casebook (pp. 69-84). Walnut Creek, CA: Altamira.

Foster, G. D., Sherman, S., Borradaile, K. E., Grundy, K. M., Vander Veur, S. S., Nachmani, J., \& Shults, J. (2008). A policy-based school intervention to prevent overweight and obesity. Pediatrics, 121(4), e794-802.

Guo, S. S., Roche, A. F., Chumlea, W. C., Gardner, J. D., \& Siervogel, R. M. (1994). The predictive value of childhood body mass index values for overweight at age $35 \mathrm{y}$. American Journal of Clinical Nutrition, 59, 995-999.

Holt, K., Wooldridge, N., Story, M., \& Sofka, D. (Eds.). (2011). Bright futures: Nutrition (3rd ed.). Elk Grove Village, IL: American Academy of Pediatrics.

Johnson, S. L., Clark, L., Goree, K., O'Connor, M., \& Zimmer, L. M. (2008). Healthcare providers' perceptions of the factors contributing to infant obesity in a low-income Mexican American community. Journal for Specialists in Pediatric Nursing, 13(3), 180-190.

Kay, M. (1977). Health and illness in a Mexican American barrio. In E. H. Spicer (Ed.), Ethnic medicine in the Southwest (pp. 99-166). Tucson: University of Arizona Press.

Keller, C. S. \& Cantue, A. (2008). Camina por salud: Walking in Mexican-American women. Applied Nursing Research, 21, 110-113.

Kramer, M. S., Barr, R. G., Leduc, D. G., Boisjoly, C., \& Pless, I. B. (1983). Maternal psychological determinants of infant obesity: Development and testing of two new instruments. Journal of Chronic Disease, 36, 329-335.

Marín, G., Sabogal, F., Marín, B., Otero-Sabogal, R., \& Perez-Stable, E. (1987). Development of a short acculturation scale for Hispanics. Hispanic Journal of Behavioral Sciences, 9(183), 183-205.

Morgan, D. L., \& Krueger, R. A. (1993). When to use focus groups and why. In D. L. Morgan (Ed.), Successful focus groups: Advancing the state of the art (pp. 3-19). Newbury Park, CA: Sage.

Morse, J. M. (2001). Qualitative verification: Building evidence by extending basic findings. In J. M. Morse, J. M. Swanon, \& A. J. Kuzel, The nature of qualitative evidence (pp. 203-220). Thousand Oaks, CA: Sage.

National Association of Pediatric Nurse Practitioners (NAPNAP). (2006). Healthy eating and activity together $\left(H E A T^{\mathrm{TM}}\right)$ clinical practice guideline: Identifying and preventing overweight in childhood. Cherry Hill, $\mathrm{NJ}$ : NAPNAP.

Ogden, C. L., Carroll, M. D., Curtin, L. R., Lamb, M. M., \& Flegal, K. M. (2010). Prevalence of high body mass index in US children and adolescents, 2007-2008. JAMA, 303, 242-249.

Ogden, C. L., Carroll, M. D., Curtin, L. R., McDowell, M. A., Tabak, C. J., \& Flegal, K. M. (2006). Prevalence of overweight and obesity in the United States, 1999-2004. JAMA, 295, 1549-1555.

Ogden, C. L., Carroll, M. D., Kit, B. K., \& Flegal, K. M. (2012). NCHS data brief: Prevalence of obesity in the United States, 2009-2010. Retrieved from: http://www.cdc.gov/nchs/data/databriefs/db82.pdf.

Ogden, C. L., Flegal, K. M., Carroll, M. D., \& Johnson, C. I. (2002). Prevalence and trends in overweight among US children and adolescents, 1999-2000. JAMA, 288, 1728-1732.

Spradley, J. P. (1980). Participant observation. New York: Holt, Rinehart \& Winston.

Vega, W. A., Rodriguez, M. A., \& Gruskin, E. (2009). Health disparities in the Latino population. Epidemiologic Reviews, 31, 99-112. 


\section{Lauren Clark et al.}

Weller, S., \& Romney, A. K. (1988). Systematic data collection. Newbury Park, CA: Sage.

Whitaker, R. (1997). Predicting obesity in young adulthood from childhood and parental obesity. New England Journal of Medicine, 337, 869-873.

Young, J., \& O'Connor, M. E. (2005). Risk factors associated with latent tuberculosis infection in MexicanAmerican children. Pediatrics 115(5), e647-653. 